\title{
Prediction of Oilfield-Increased Production Using Adaptive Neurofuzzy Inference System with Smoothing Treatment
}

\author{
Lin Chen $\mathbb{D},{ }^{1,2}$ Zhibin Liu, ${ }^{1}$ Nannan Ma $\mathbb{D},{ }^{1}$ and Yi Wang ${ }^{3}$ \\ ${ }^{1}$ School of Science, Southwest Petroleum University, Chengdu 610500, Sichuan, China \\ ${ }^{2}$ Institute for Artificial Intelligence, Southwest Petroleum University, Chengdu 610500, Sichuan, China \\ ${ }^{3}$ Shixi Field Operation District of Xinjiang Oilfield Company, PetroChina, Karamay 834000, China \\ Correspondence should be addressed to Lin Chen; chenlin8976@163.com
}

Received 23 August 2019; Accepted 22 October 2019; Published 19 December 2019

Academic Editor: Arturo Pagano

Copyright (C) 2019 Lin Chen et al. This is an open access article distributed under the Creative Commons Attribution License, which permits unrestricted use, distribution, and reproduction in any medium, provided the original work is properly cited.

\begin{abstract}
A novel modified adaptive neurofuzzy inference system with smoothing treatment (MANFIS) is proposed. The MANFIS model considered the smoothing treatment of initial data basing on the adaptive neurofuzzy inference system, and we used it to predict oilfield-increased production under the well stimulation. Numerical experiments show the prediction result of the novel considering smoothing treatment is better than that without smoothing treatment. This study provides a novel and feasible method for prediction of oilfield-increased production under well stimulation, and it can be helpful in the further study of oilfield development measure planning.
\end{abstract}

\section{Introduction}

We all know, oil is the strategic energy of the country, and the geological structure of the reservoir is complex [1], especially in China. Measures to increase production are necessary when oilfield development reaches a certain period and are diverse [2]. The common measures are carbon dioxide huff and puff, fracturing, acid fracturing, plugging removal, back production, and so on. The type of reservoir are various, such as shallow natural water drive reservoirs, middle and deep water injection development reservoirs, deep-low permeability reservoirs, dissolved gas drive reservoirs, and buried hill carbonate reservoirs . Each well stimulation has its characteristics and each reservoir has its own unique geological parameters. Measures to increase production are affected by many factors and the effect of increasing oil is different for different measures $[3,4]$. Measures to increase oil production affect the economic benefit of the whole oilfield, and the accurate prediction of oilfield-increased production under the well stimulation can maximize the economic benefit of the oil field $[5,6]$. Prediction of oilfield-increased production is an important basis for the adjustment of oilfield development scheme [7], so it is of great significance to study the prediction method of oilfield-increased production under the well stimulation.

Artificial network-based fuzzy inference system (ANFIS) was proposed by Jang [8], and the system has been widely applied to research on prediction, such as drought forecasting, predicting sediment transport in clean sewer, wind power forecasting, estimation of elastic constant of rocks, prediction of swell potential of clayey soils, hydrologic model prediction, and hydropower stream flow forecasting [9-15]. Over the past two decades, many experts and scholars have improved the performance of the artificial network-based fuzzy inference system. Dehghani et al. [16] added the grey wolf optimization to adaptive the neurofuzzy inference system and improved the prediction performance of the ANFIS. Mostafaei et al. [17] evaluate and compare the prediction and simulating efficiency of the response surface methodology and adaptive neurofuzzy inference system. Mostafaei [18] designed ANFIS models and generated three fuzzy inference systems structures: grid partition, subtractive clustering, and fuzzy c-means, which are to predict the cetane number of biodiesel. Aghbashlo et al. [19] interfaced three different fuzzy 
optimization methods with the adaptive neurofuzzy inference system as a modeling system. Janiga et al. and Sayyafzadeh $[20,21]$ give the different self-adaptive methods. Vardian et al. [22] obtained an excellent ANFIS model with low error, which presented all data influencing the reservoir characteristics to the ANFIS. Haghiabi et al. [23] predicted the discharge coefficient of triangular labyrinth weir using the multilayer perceptron neural network and adaptive neurofuzzy inference system. Janiga et al. [24] employed nature-inspired optimization algorithms to evaluate the potential of production boost, and natureinspired algorithms outperform widely, report optimization methods, and provide a higher quality solutions. Smoothing treatment is an important means in the field of mathematical research [25]. Any collected data may contain outlier point and seriously affect the accuracy of data prediction [26]. The ANFIS uses the training capability of ANN to assign and adjust the membership functions. The backpropagation algorithm enables the model to adjust the parameters until an acceptable error is reached [14]. For this purpose, the adaptive neurofuzzy inference system (ANFIS) was coupled with smoothing treatment to forecast the oilfield-increased production based on the measured data. This method is capable to facilitate the prediction of oilfield-increased production.

This paper presents novelties in two aspects. The first: the optimization adaptive neurofuzzy inference system with smoothing treatment and the operation flow of the novel method is built. The second: the optimization adaptive neurofuzzy inference system with smoothing treatment is applied to prediction of oilfield-increased production under the well stimulation.

The rest of the paper is organized as follows. In Section 2 , we introduced the study experimental dataset and the details of ANFIS modeling with smoothing treatment. In Section 3, we carry out numerical experiment and analysis of model application. Finally, we draw our conclusions in Section 4.

\section{Materials and Methods}

2.1. Description of the Study Experimental Dataset. The geological structure of the oil reservoir is complex, especially in China. A large oilfield contains a variety of reservoir geological types, such as shallow natural water flooding reservoir, low-permeability reservoir, and medium-permeability reservoir. The primary purpose of oilfield development is to increase production. It is necessary to carry out well stimulation to increase production, and the oilfield well stimulation includes multiple types, such as carbon dioxide huff and puff, minus punch, and fracturing. The effect of different well stimulation on increasing production is different, and well stimulation is affected by a variety of factors. So, prediction of increasing oil production according to the changed data of factors affecting the well stimulation, which is a complex multifactor dynamic change prediction problem.
In this paper, prediction of oilfield-increased production was studied under two well stimulations: carbon dioxide huff and puff and fracturing. There are many factors affecting the oilfield-increased production of carbon dioxide huff and puff well stimulation, including remaining oil saturation, reservoir thickness, formation pressure coefficient, number of huff and puff, viscosity, natural fracture permeability, porosity, artificial fracture permeability, artificial fracture length, and injection-production technology. But, some factors are unchanged in the process of oilfield production. The statistics of some factors are difficul. Considering all the factors of well stimulation, we can accurately predict the increased production by well stimulation, but it is impossible or difficult to obtain the data of all influencing factors. To an extent, some factors can reflect the law of increased production. So, according to the actual oilfield development data, only four main control factors affecting the increased production of well stimulation were selected, the main control factors are shown in Table 1, and the main control factors can be adjusted according to the actual monitoring data of the oilfield. Figure 1 shows the oilfield monthly increased production of carbon dioxide huff and puff well stimulation from 2014 to 2016. Figure 2 shows the oilfield monthly increased production of fracturing well stimulation from 2015 to 2016.

2.2. Adaptive Neurofuzzy Inference System. Artificial neural network has strong self-learning and adaptive ability, but it cannot express reasoning function well. The fuzzy system has good reasoning function, but it has no adaptive ability. Jang developed the adaptive neurofuzzy inference system (ANFIS) [8], which includes the advantages of neural network learning mechanism and fuzzy system reasoning ability. Generally, the T-S fuzzy model is transformed into an adaptive network in order to realize the learning process of the model, and the general schematic architecture of the adaptive neurofuzzy inference system is shown in Figure 3, which includes five layers. All are fixed nodes, except the first and fourth nodes, which are adaptive nodes. Figure 3 shows the architecture of the adaptive neurofuzzy inference system with two inputs. However, in the paper we studied the adaptive neurofuzzy inference system with four inputs, and the adaptive neurofuzzy inference system with four inputs, as shown in Figure 4.

The adaptive network is a multilayer feedforward network. The parameters of the nodes are obtained by data training. The significance of each layer is given for the adaptive neurofuzzy inference system with $n$ inputs as follows $[16,27]$ :

Layer 1: it is the membership function layer of the input variable, which is responsible for fuzzification of the input signal. The nodes act adaptive in generating the membership grades of the inputs and the node $i$ has an output function: 
TABLE 1: Main control factors of well stimulation.

\begin{tabular}{lcc}
\hline Well stimulations & Carbon dioxide huff and puff & Fracturing \\
\hline & Remaining oil saturation $(x 1)$ & Remaining oil saturation $(y 1)$ \\
Main control factors & Reservoir thickness $(x 2)$ & Reservoir thickness $(y 2)$ \\
& Formation pressure coefficient $(x 3)$ & Formation pressure coefficient $(x 3)$ \\
& Number of huff and puff $(x 4)$ & Expected fracture radius $(y 4)$ \\
\hline
\end{tabular}

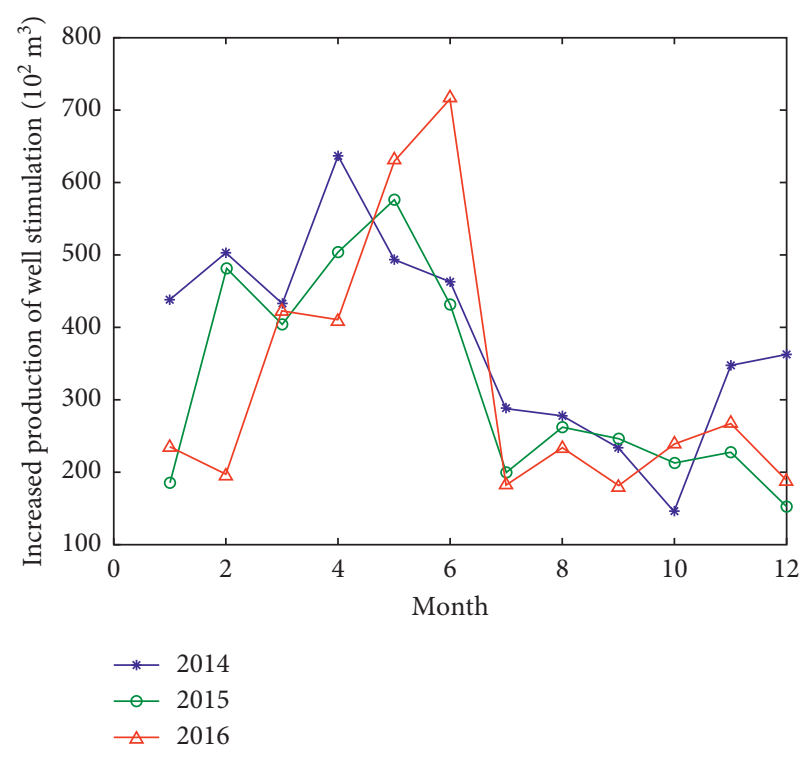

FIGURE 1: Increased production of carbon dioxide huff and puff from 2014 to 2016.

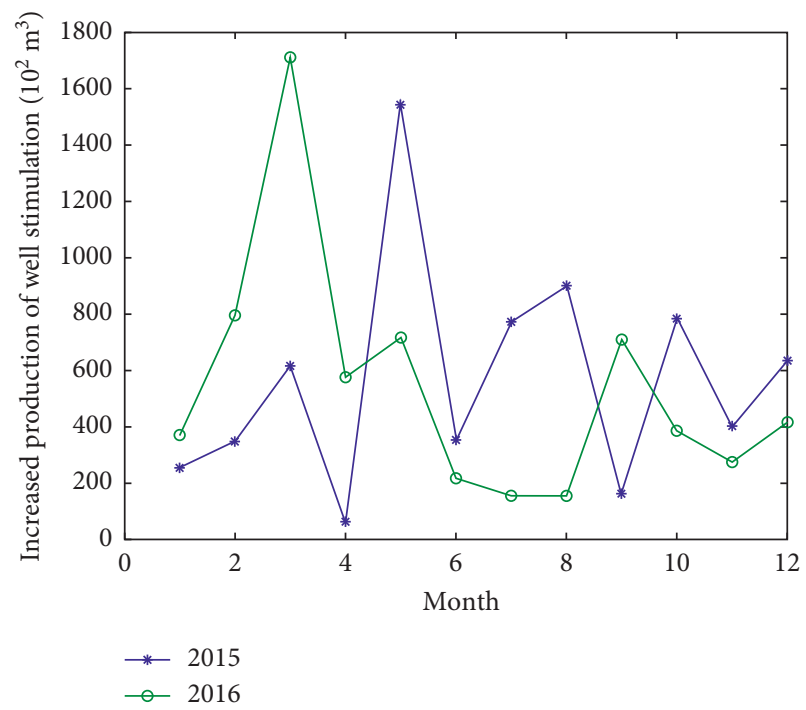

Figure 2: Increased production of fracturing from 2014 to 2016.

$$
\begin{aligned}
O_{i}^{1}=\mu_{A_{i}}(x), & i=1,2, \ldots, n, \\
\text { or } O_{i}^{1}=\mu_{B_{i}}(y), & i=1,2, \ldots, n,
\end{aligned}
$$

where $x$ and $y$ is the input of node $i, A_{i}$ and $B_{i}$ are the fuzzy sets. $n$ is the number of inputs. $O_{i}^{1}$ is the membership function value of $A_{i}$ and $B_{i}$, where indicates the degree of $x$ and $y$ belongs to $A_{i}, B_{i}$. Membership function $\mu_{A_{i}}$ and $\mu_{B_{i}}$ depend on the front piece parameters.

Layer 2: it is the regular strength release layer. In this layer, the signals are multiplied at the node:

$$
O_{i}^{2}=\omega_{i}=\mu_{A_{i}}(x) \times \mu_{B_{i}}(y), \quad i=1,2, \ldots, n .
$$

Layer 3: it is the normalization layer. The normalization reliability of the rule $i$ is calculated at the node $i$ :

$$
O_{i}^{3}=\bar{\omega}_{i}=\frac{\omega_{i}}{\omega_{1}+\omega_{2}+\cdots+\omega_{n}}, \quad i=1,2, \ldots, n
$$

Layer 4: it is the output layer for calculating the fuzzy rule. Each node in this layer is an adaptive node in the layer and the output of node $i$ is

$O_{i}^{4}=\bar{\omega}_{i} f_{i}=\bar{\omega}_{i}\left(p_{i} x+q_{i} x+r_{i}\right), \quad i=1,2, \ldots, n$,

where $\bar{\omega}_{i}$ is the output of layer $3 .\left\{p_{i}, q_{i}, r_{i}\right\}$ is the parameter set and it is also called the postpiece parameter. Layer 5: it is a fixed node and it calculates the total output of all input signals:

$$
O^{5}=\sum \bar{\omega}_{i} f_{i}=\frac{\sum \omega_{i} f_{i}}{\sum \omega_{i}}, \quad i=1,2, \ldots, n .
$$

If the previous parameters are determined, the output of the adaptive neurofuzzy inference system can be represented as a linear combination of the postpiece parameter:

$$
O^{5}=\sum_{i=1}^{n} \bar{\omega}_{i} f=\sum_{i=1}^{n}\left(\left(\bar{\omega}_{i} x\right) p_{1}+\left(\bar{\omega}_{i} y\right) q_{1}+\bar{\omega}_{i} r_{1}\right) .
$$

2.3. ANFIS with Smoothing Treatment. The purpose of smoothing treatment is to eliminate the outliers of the original monitoring data and to increase the credibility of the prediction index. $X$ is the time series of the monitoring indicator. $X=\left\{X_{1}, X_{2}, \ldots, X_{m}, X_{m+1}\right\} . X_{1}, X_{2}, \ldots, X_{m}$ are the control index time series and $Y$ is the prediction index time series. The control index determines the changing trend of the prediction index. $\bar{X}_{1}, \bar{X}_{2}, \ldots, \bar{X}_{m}$ are the average values of control index time series and $\bar{Y}$ is the average value of prediction index time series. So, 


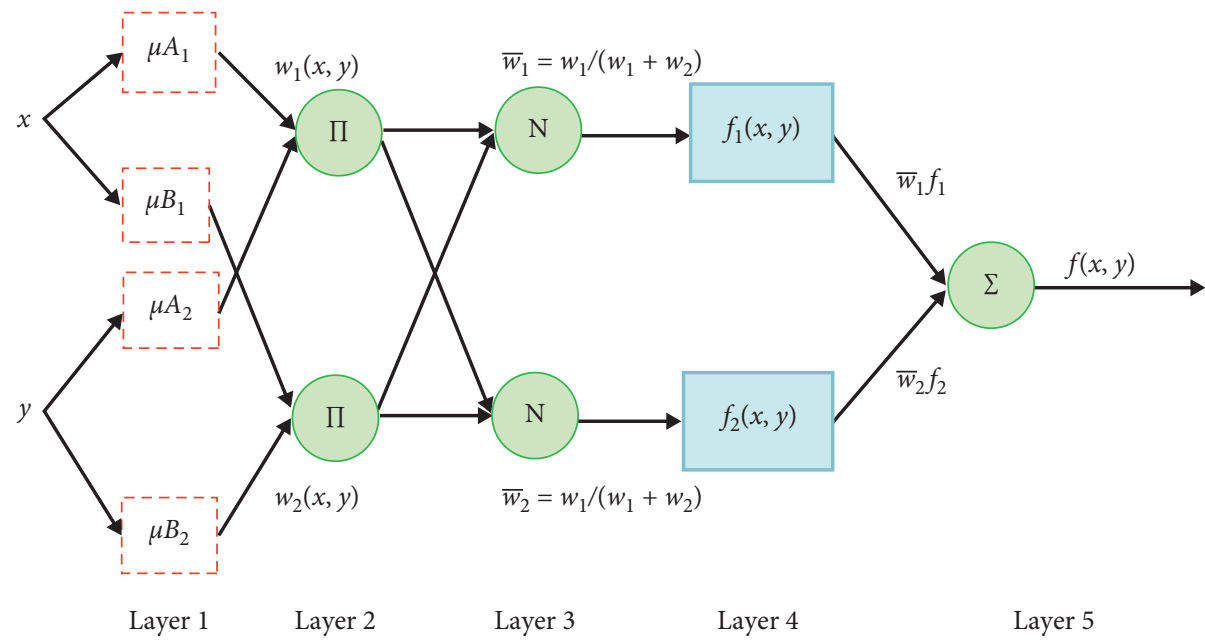

FIGURE 3: Schematic architecture of the adaptive neurofuzzy inference system [16].

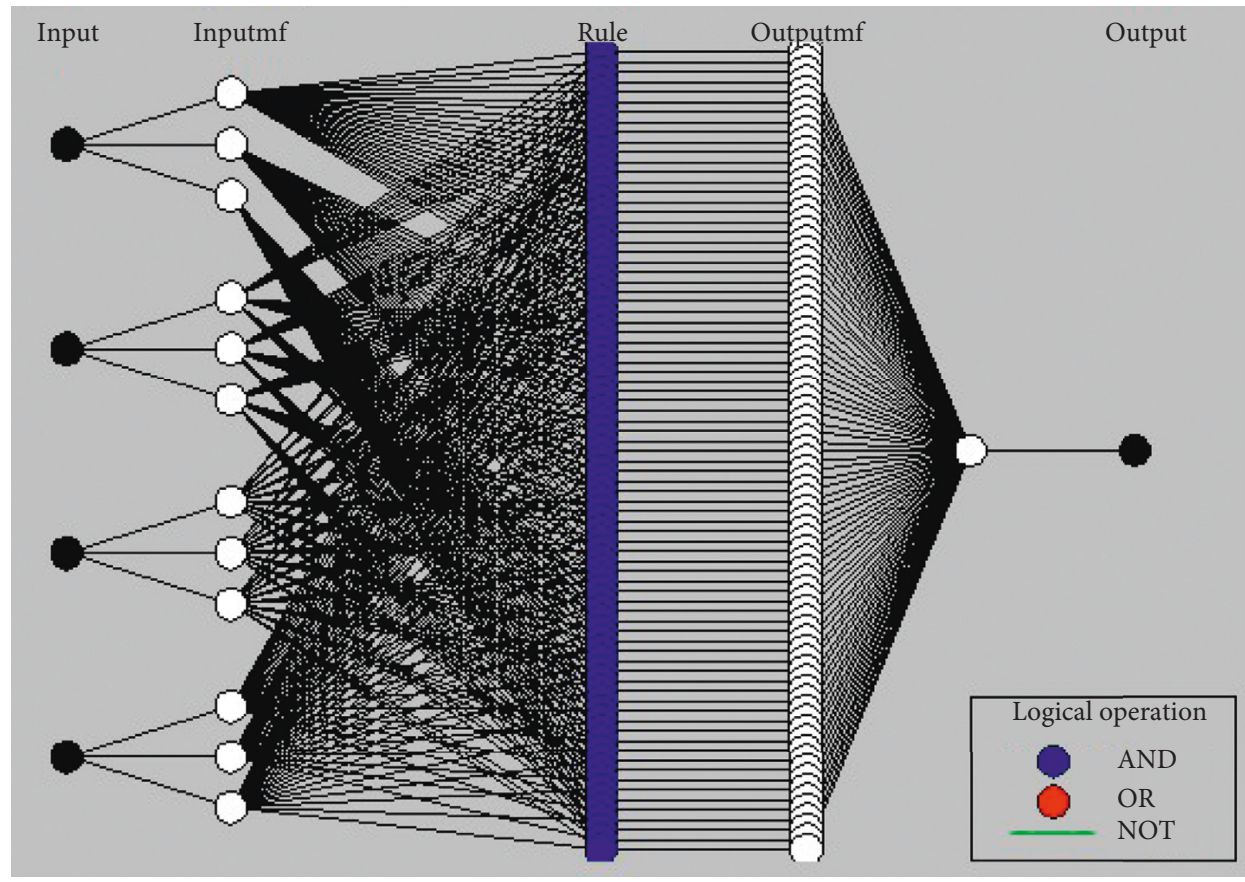

FIGURE 4: Architecture of the adaptive neurofuzzy inference system with four inputs.

$$
\begin{aligned}
X_{1} & =\left[\begin{array}{cccc}
x_{11} & x_{12} & \cdots & x_{1 n}
\end{array}\right]^{T}, \\
X & =\left[\begin{array}{cccc}
x_{11} & \cdots & x_{m 1} & y_{1} \\
x_{12} & \cdots & x_{m 2} & y_{2} \\
\vdots & \vdots & \vdots & \vdots \\
x_{1 n} & \cdots & x_{m n} & y_{n}
\end{array}\right], \\
\bar{X} & =\left[\begin{array}{llll}
\bar{X}_{1} & \cdots & \bar{X}_{m} & \bar{Y}
\end{array}\right],
\end{aligned}
$$

$$
\begin{gathered}
\bar{X}_{i}=\frac{1}{n} \sum_{j=1}^{n} x_{i j}, \\
\bar{Y}=\frac{1}{n} \sum_{i=1}^{n} Y_{i} .
\end{gathered}
$$

Find the possible outlier and smoothing treatment $X_{i}^{m a}, X_{i}^{m i} i=1,2, \ldots, m$ :

$$
X_{i}^{m a}=\max \left\{x_{i 1}-\bar{X}_{i}, x_{i 2}-\bar{X}_{i}, \ldots, x_{i n}-\bar{X}_{i}\right\} .
$$


If $X_{i}^{m a} \geq \bar{X}_{i}\left(1+\eta_{1}\right)$ and $\left(x_{i j}-\bar{X}_{i}\right) / \bar{X}_{i} \geq \zeta_{1}\left(\left(Y_{j}-\bar{Y}\right) / \bar{Y}\right)$, $\eta_{1}, \zeta_{1}>0, j=1,2, \ldots, n$, then

$$
\begin{aligned}
x_{i j} & = \begin{cases}\bar{X}_{i}, & \text { if } x_{i}-\bar{X}=X_{i}^{m a}, \\
x_{i j}, & \text { if } x_{i}-\bar{X} \neq X_{i}^{m a},\end{cases} \\
X_{i}^{m i} & =\max \left\{\bar{X}_{i}-x_{i 1}, \bar{X}_{i}-x_{i 2}, \ldots, \bar{X}_{i}-x_{i n}\right\} .
\end{aligned}
$$

If $\bar{X}_{i} \geq X_{i}^{m i}\left(1+\eta_{2}\right)$ and $\left(\bar{X}_{i}-x_{i j}\right) / x_{i j} \geq \zeta_{2}\left(\left(\bar{Y}-Y_{j}\right) / Y_{j}\right)$, $\eta_{2}, \zeta_{2}>0, j=1,2, \ldots, n$, then

$$
x_{i j}= \begin{cases}\bar{X}_{i}, & \text { if } \bar{X}-x_{i}=X_{i}^{m i} \\ x_{i j}, & \text { if } \bar{X}-x_{i} \neq X_{i}^{m i}\end{cases}
$$

where $\eta_{1}, \zeta_{1}$ and $\eta_{2}, \zeta_{2}$ are constants, which can be adjusted according to the actual situation.

Combining the theory of smoothing treatment and ANFIS, Figure 5 shows the flowchart of the ANFIS with smoothing treatment.

\section{Application and Analysis}

In this section, we will present prediction of oilfield-increased production using the optimization adaptive neurofuzzy inference system with smoothing treatment, including application of model, model appraisal, application results, and discussion.

3.1. Raw Data. Monofactor analysis is an effective method for prediction of oilfield-increased production under the well stimulation. To study the influence of well stimulation on increased production should be to implement well stimulation in 1-well and to change one factor and ensure that other factors remain unchanged at the same time. But the cycle of well stimulation is long in oilfield, and it is impossible or difficult to use monofactor analysis to implement the same well stimulation for the same well many times. So, it is impossible to obtain the multiple parameters of well stimulation and production increases for the same oil well. But, the wells are numerous in the oilfield, and geological parameters are similar in the same oilfield. To a certain extent, a block of an oilfield can be regarded as a "single well" and the average value of the major factors and increased production can be regarded as the parameters of the "single well." So, the average of the parameters of well stimulation and production increases was calculated as the time series in this paper. 36 months of carbon dioxide huff and puff measures to increase production data from 2014 to 2016 were obtained, and 24 months of fracturing measures to increase production data from 2015 to 2016 were obtained. Time series of measures to increase production for carbon dioxide huff and puff was shown in Table 2, where (1) stand for dimensionless. Time series of No. 1-No. 30 was used for training ANFIS, and time series of No. 31-No. 36 was used for verify the accuracy of the ANFIS. Time series of measures to increase production for fracturing was shown in

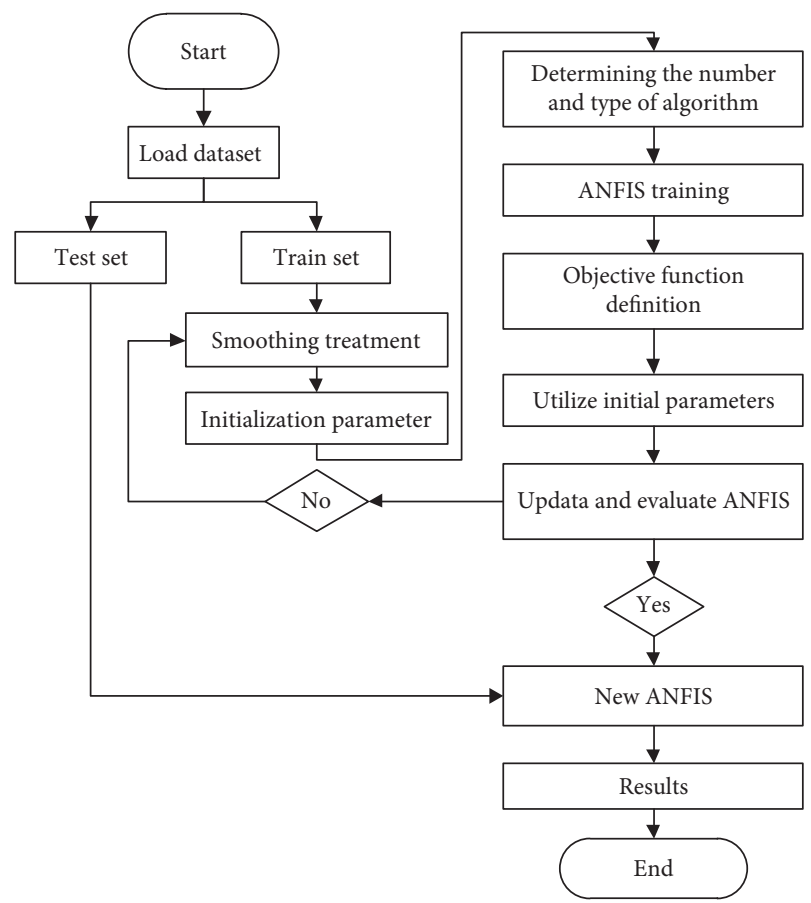

FIgURE 5: The flowchart of the ANFIS with smoothing treatment.

Table 3. Time series of No. 1-No. 21 was used for training ANFIS, and time series of No. 22-No. 24 was used for verify the accuracy of the ANFIS.

3.2. Model Appraisal. Three statistical criteria are utilized for appraisal of the predictive performance of the model, which are coefficient of determination $\left(R^{2}\right)$, root mean squared error (RMSE), and mean absolute percentage error (MAPE).

$R^{2}$ is used to recognize the goodness of fit between observed and modeled data values, which is defined as follows:

$$
R^{2}=1-\frac{\sum_{i=1}^{m}\left(x_{i, e}-x_{i, p}\right)^{2}}{\sum_{i=1}^{m}\left(x_{i, p}-x_{e, a}\right)^{2}} .
$$

The RMSE is one of the most commonly reported measures of disagreement and indicate the accuracy of predictions, which is defined as follows:

$$
\text { RMSE }=\sqrt{\frac{1}{m} \sum_{i=1}^{m}\left(x_{i, p}-x_{i, e}\right)^{2} .}
$$

The MAPE is used to evaluate the overall forecast performance of the prediction models, which is defined as follows:

$$
\text { MAPE }=\frac{1}{m} \sum_{i=1}^{m}\left|\frac{x_{i, e}-x_{i, p}}{x_{i, e}}\right| \times 100(\%),
$$


TABLE 2: Increased production of carbon dioxide huff and puff.

\begin{tabular}{|c|c|c|c|c|c|}
\hline No. & $x 1(\%)$ & $x 2(\mathrm{~m})$ & $x 3(1)$ & $x 4(1)$ & Increased production $\left(10^{2} \mathrm{~m}^{3}\right)$ \\
\hline 1 & 42.58 & 119.41 & 0.93 & 2.00 & 438.27 \\
\hline 2 & 42.67 & 141.07 & 0.90 & 2.00 & 503.25 \\
\hline 3 & 53.00 & 117.58 & 0.90 & 2.00 & 433.28 \\
\hline 4 & 43.25 & 185.30 & 0.90 & 2.00 & 636.83 \\
\hline 5 & 43.58 & 139.48 & 0.90 & 1.00 & 493.87 \\
\hline 6 & 44.17 & 124.90 & 0.90 & 3.00 & 463.00 \\
\hline 7 & 43.08 & 69.37 & 0.90 & 2.00 & 288.77 \\
\hline 8 & 44.33 & 65.22 & 0.90 & 2.00 & 278.20 \\
\hline 9 & 46.81 & 51.31 & 0.87 & 1.00 & 234.03 \\
\hline 10 & 44.42 & 23.29 & 0.95 & 1.00 & 146.79 \\
\hline 11 & 46.42 & 287.31 & 0.95 & 2.00 & 347.82 \\
\hline 12 & 40.84 & 95.17 & 0.94 & 2.00 & 363.00 \\
\hline 13 & 41.83 & 35.63 & 0.90 & 2.00 & 185.68 \\
\hline 14 & 45.08 & 130.69 & 0.71 & 3.00 & 481.78 \\
\hline 15 & 41.83 & 106.55 & 0.90 & 3.00 & 404.45 \\
\hline 16 & 42.33 & 141.55 & 0.90 & 2.00 & 504.20 \\
\hline 17 & 44.00 & 164.77 & 0.90 & 2.00 & 576.35 \\
\hline 18 & 44.83 & 114.19 & 0.90 & 3.00 & 431.88 \\
\hline 19 & 43.17 & 39.57 & 0.90 & 2.00 & 199.50 \\
\hline 20 & 43.25 & 58.48 & 0.90 & 3.00 & 262.35 \\
\hline 21 & 44.02 & 54.65 & 0.93 & 2.00 & 246.14 \\
\hline 22 & 41.37 & 44.81 & 0.94 & 2.00 & 212.69 \\
\hline 23 & 43.13 & 46.95 & 0.95 & 3.00 & 227.81 \\
\hline 24 & 43.96 & 23.53 & 0.93 & 2.00 & 152.71 \\
\hline 25 & 44.97 & 50.40 & 0.91 & 2.00 & 234.76 \\
\hline 26 & 40.85 & 39.30 & 0.92 & 2.00 & 195.33 \\
\hline 27 & 38.17 & 112.79 & 0.95 & 3.00 & 422.13 \\
\hline 28 & 41.08 & 107.08 & 0.92 & 3.00 & 408.53 \\
\hline 29 & 43.50 & 182.03 & 0.90 & 3.00 & 631.03 \\
\hline 30 & 41.92 & 209.60 & 0.90 & 3.00 & 716.96 \\
\hline 31 & 43.08 & 31.98 & 0.90 & 3.00 & 182.60 \\
\hline 32 & 43.00 & 48.83 & 0.90 & 3.00 & 233.05 \\
\hline 33 & 38.17 & 33.23 & 0.95 & 3.00 & 179.22 \\
\hline 34 & 39.55 & 54.49 & 0.95 & 2.00 & 239.06 \\
\hline 35 & 44.51 & 61.64 & 0.87 & 2.00 & 267.60 \\
\hline 36 & 37.32 & 38.51 & 0.95 & 2.00 & 187.76 \\
\hline
\end{tabular}

where $x_{i, e}$ is the actual values, $x_{i, p}$ is the predicted values, and $x_{i, a}$ is the average of the actual values.

3.3. Results and Discussion. Increased production versus the control index of fracturing and carbon dioxide huff and puff well stimulation is shown in Figures 6 and 7, which shows the relationship between any two main control factors and increased production. The main control factors of carbon dioxide huff and puff well stimulation are remaining oil saturation $(x 1)$, reservoir thickness $(x 2)$, formation pressure coefficient ( $x 3$ ), and number of huff and puff ( $x 4)$. Input 1 , input 2 , input 3 , and input 4 stand for $x 1$, $x 2, x 3$, and $x 4$, respectively, and the output stands for oilfield-increased production.

In this paper, only four factors were considered, which affect the carbon dioxide huff and puff measure to increase production. The effects of different factors on increase production may be different. There are six possible pairwise combinations of the four factors, and the combination of any two factors will have a specific impact on the increase production. Figure 6 shows the six pairwise combinations affecting the increased production for the $\mathrm{CO}_{2}$ huff and puff well stimulation.

The main control factors of fracturing well stimulation are remaining oil saturation $(y 1)$, reservoir thickness $(y 2)$, permeability $(y 3)$, and expected fracture radius $(y 4)$. Input 1 , input 2, input 3, and input 4 stand for $y 1, y 2, y 3$, and $y 4$, respectively, and the output stands for oilfield-increased production. Similar to Figure 6, Figure 7 shows the six pairwise combinations affecting the increased production for the fracturing well stimulation.

The predictive capability of ANFIS and MANFIS models were compared using statistical criteria, i.e., $R^{2}, \mathrm{RMSE}$, and MAPE. The established smoothing treatment model and traditional ANFIS were performed to construct the novel models in order to predict the experimental data. The comparison of statistical criteria of the increased production from carbon dioxide huff and puff well stimulation is given in Table 4. The $R^{2}$ values for MANFIS and ANFIS models (for all prediction data) are found to be 0.9968 and 0.9601 , respectively, the RMSE for MANFIS and ANFIS models are 
TABLE 3: Increased production of fracturing.

\begin{tabular}{|c|c|c|c|c|c|}
\hline No. & $y 1(\%)$ & $y 2(\mathrm{~m})$ & $y 3\left(10^{-3} \mu \mathrm{m}^{2}\right)$ & $y 4(\mathrm{~m})$ & Increased production $\left(10^{2} \mathrm{~m}^{3}\right)$ \\
\hline 1 & 46.84 & 17.60 & 19.62 & 84.00 & 417.11 \\
\hline 2 & 64.06 & 21.73 & 38.85 & 81.67 & 464.20 \\
\hline 3 & 43.87 & 35.90 & 25.14 & 96.00 & 502.99 \\
\hline 4 & 46.55 & 16.07 & 45.48 & 97.33 & 528.68 \\
\hline 5 & 42.97 & 36.47 & 27.64 & 95.00 & 506.24 \\
\hline 6 & 39.93 & 10.20 & 17.30 & 90.43 & 414.54 \\
\hline 7 & 41.57 & 19.20 & 21.50 & 88.90 & 437.37 \\
\hline 8 & 39.50 & 18.47 & 23.50 & 114.47 & 459.00 \\
\hline 9 & 40.57 & 22.37 & 21.57 & 104.67 & 497.37 \\
\hline 10 & 38.50 & 12.67 & 37.47 & 96.50 & 491.74 \\
\hline 11 & 42.20 & 14.40 & 39.79 & 93.00 & 491.86 \\
\hline 12 & 46.98 & 13.73 & 28.17 & 90.63 & 456.10 \\
\hline 13 & 42.93 & 14.40 & 18.34 & 87.67 & 417.55 \\
\hline 14 & 42.30 & 19.60 & 44.83 & 106.00 & 559.75 \\
\hline 15 & 49.03 & 63.20 & 21.40 & 100.00 & 559.43 \\
\hline 16 & 53.30 & 9.00 & 52.93 & 89.27 & 534.53 \\
\hline 17 & 41.80 & 19.47 & 80.73 & 90.97 & 479.99 \\
\hline 18 & 45.83 & 18.27 & 43.67 & 110.07 & 571.68 \\
\hline 19 & 47.80 & 13.67 & 19.73 & 94.63 & 448.56 \\
\hline 20 & 44.92 & 18.10 & 33.21 & 103.00 & 518.44 \\
\hline 21 & 42.73 & 20.83 & 79.17 & 85.70 & 581.36 \\
\hline 22 & 44.43 & 22.25 & 32.60 & 95.38 & 497.03 \\
\hline 23 & 45.20 & 14.93 & 19.50 & 92.70 & 441.13 \\
\hline 24 & 45.94 & 17.07 & 17.45 & 109.93 & 570.38 \\
\hline
\end{tabular}

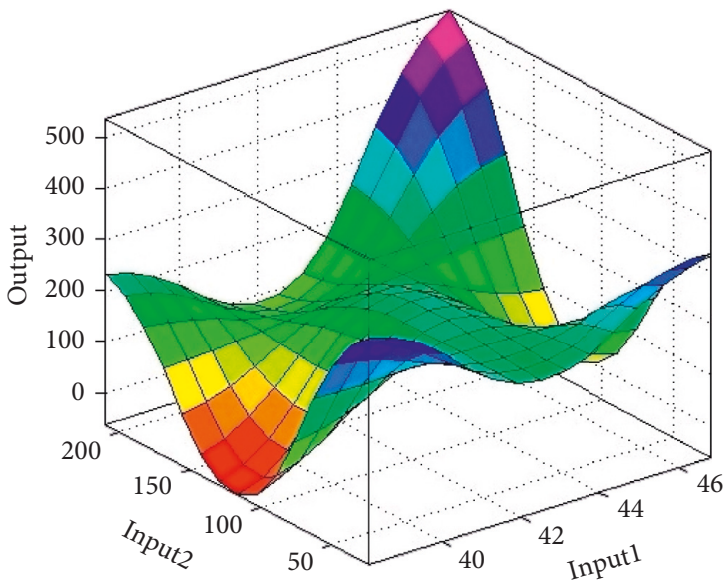

(a)

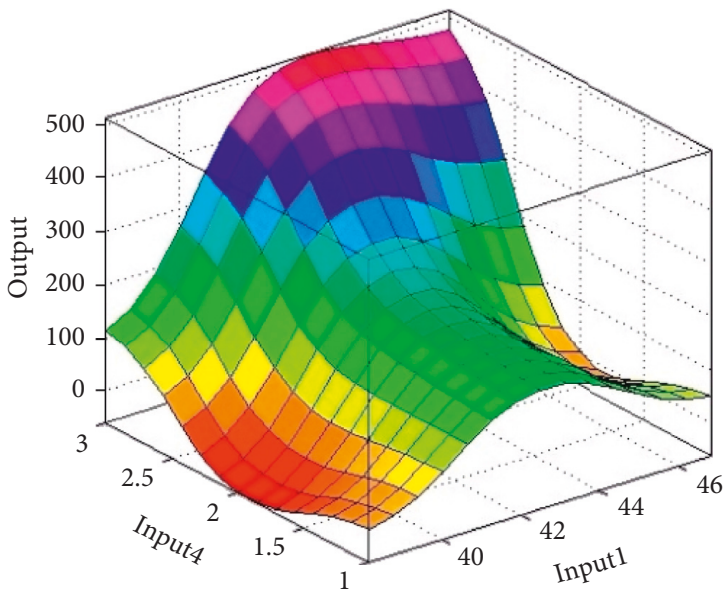

(c)

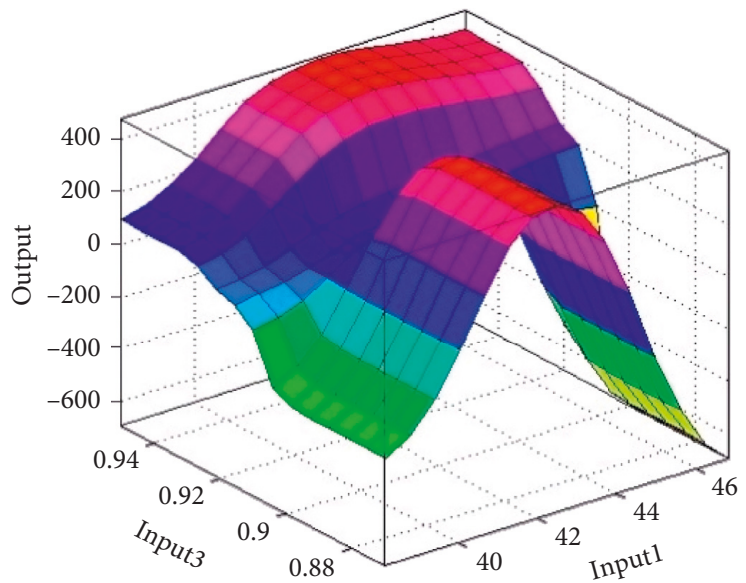

(b)

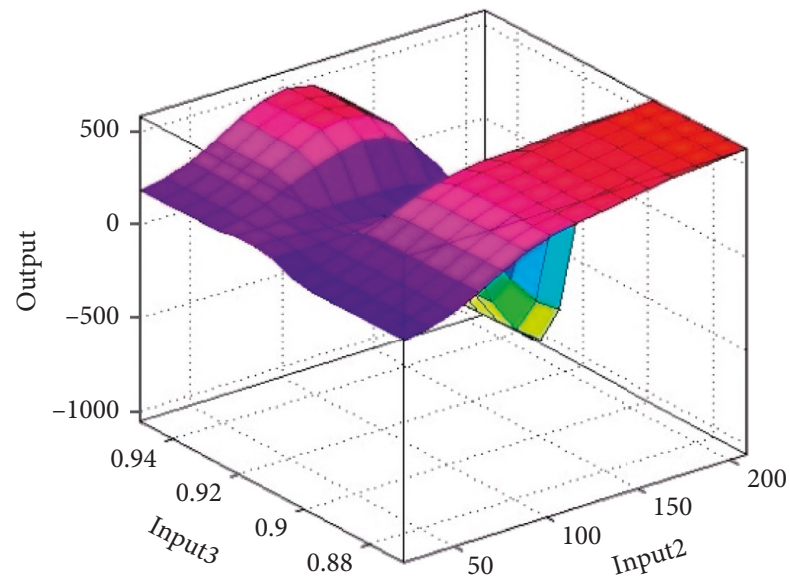

(d)

Figure 6: Continued. 


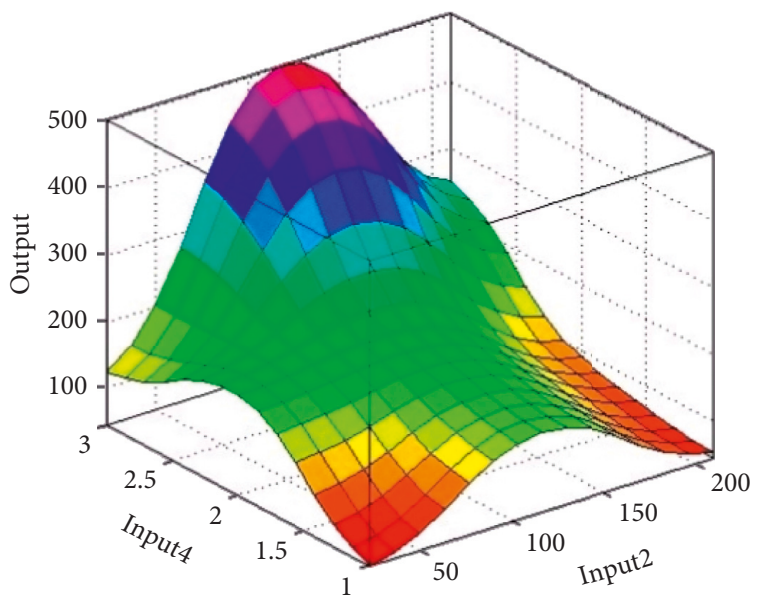

(e)

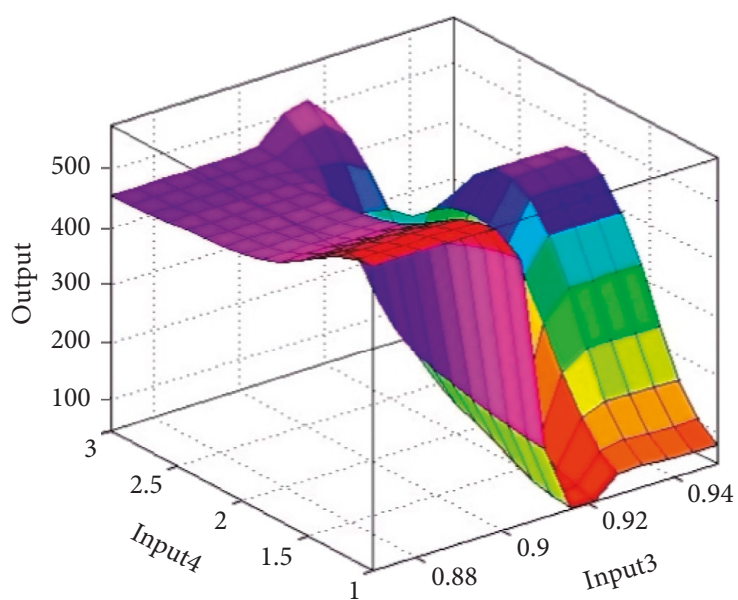

(f)

FIgURE 6: Increased production $\left(10^{2} \mathrm{~m}^{3}\right)$ versus the control index of $\mathrm{CO}_{2}$ huff and puff.

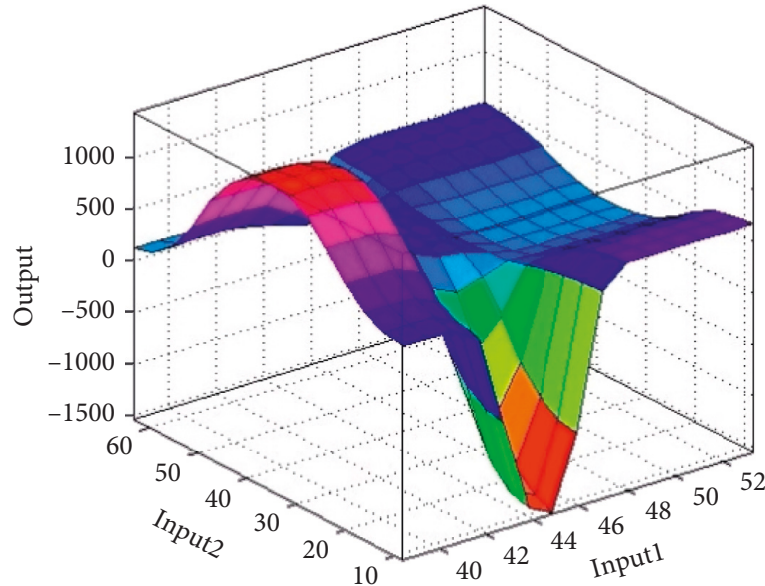

(a)

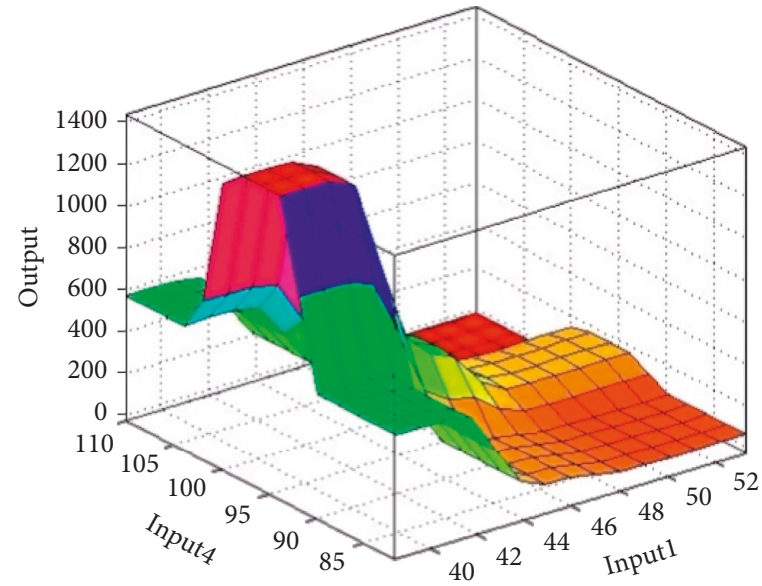

(c)

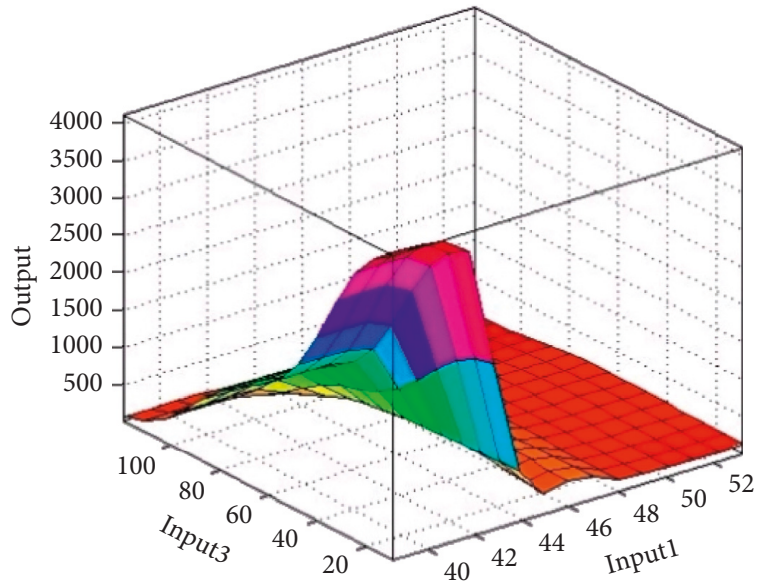

(b)

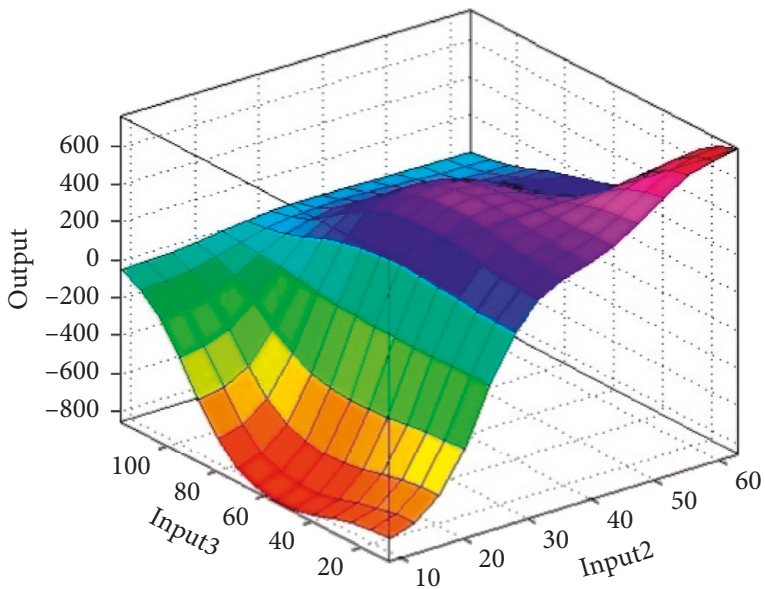

(d)

Figure 7: Continued. 


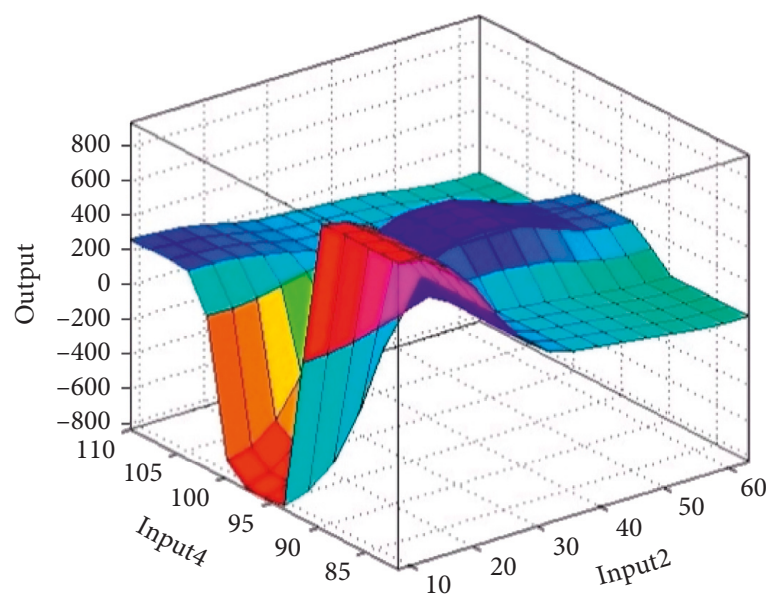

(e)

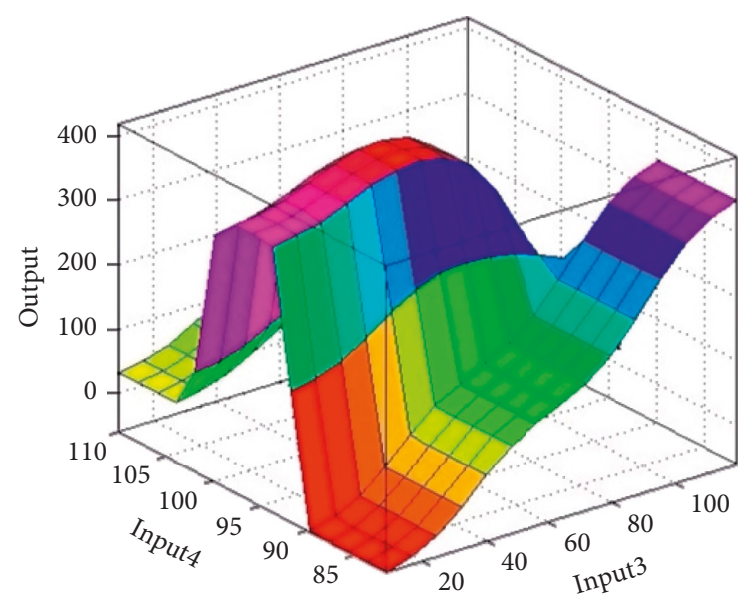

(f)

FIgURE 7: Increased production $\left(10^{2} \mathrm{~m}^{3}\right)$ versus the control index of fracturing.

TABLE 4: Results and appraisal of carbon dioxide huff and puff.

\begin{tabular}{lccc}
\hline No. & Monitoring value $\left(\mathrm{m}^{3}\right)$ & Predicted value with smoothing $\left(\mathrm{m}^{3}\right)$ & Predicted value without smoothing $\left(\mathrm{m}^{3}\right)$ \\
\hline 31 & 182.60 & 183.77 & 182.53 \\
32 & 233.05 & 233.39 & 232.05 \\
33 & 179.22 & 175.13 & 161.04 \\
34 & 239.06 & 237.88 & 237.63 \\
35 & 267.60 & 267.74 & 268.4 \\
36 & 187.76 & 185.97 & 187.42 \\
Appraisal & & & 0.9601 \\
R2 & & $\mathbf{0 . 9 9 6 8}$ & 7.4646 \\
RMSE & & $\mathbf{1 . 9 5 0 6}$ & 1.9483 \\
MAPE & & $\mathbf{0 . 7 6 1 3}$ & \\
\hline
\end{tabular}

TABLE 5: Results and appraisal of fracturing.

\begin{tabular}{lccc}
\hline No. & Monitoring value $\left(\mathrm{m}^{3}\right)$ & Predicted value with smoothing $\left(\mathrm{m}^{3}\right)$ & Predicted value without smoothing $\left(\mathrm{m}^{3}\right)$ \\
\hline 22 & 497.03 & 494.97 & 511.95 \\
23 & 441.13 & 440.84 & 442.04 \\
24 & 507.38 & 502.19 & 389.87 \\
Appraisal & & & -0.2814 \\
R2 & & $\mathbf{0 . 9 8 6 2}$ & 68.3911 \\
RMSE & & $\mathbf{3 . 2 2 8 2}$ & 8.7894 \\
MAPE & $\mathbf{0 . 5 0 1 0}$ & \\
\hline
\end{tabular}

1.9506 and 7.4646, respectively, and the MAPE for MANFIS and ANFIS models are 0.7613 and 1.9483 , respectively. The comparison of statistical criteria of the increase production from fracturing well stimulation is given in Table 5. The $R^{2}$ values for MANFIS and ANFIS models (for all prediction data) are found to be 0.9862 and -0.2814 , respectively, the RMSE for MANFIS and ANFIS models are 3.2282 and 68.3911, respectively, and the MAPE for MANFIS and ANFIS models are 0.5010 and 8.7894 , respectively. The MANFIS model has higher $R^{2}$ compared to the traditional ANFIS model and the deviations of the predicted is relatively small for the MANFIS model compared to the ANFIS model. The results confirmed that the MANFIS model is more accurate in predicting the values of increased production under the well stimulation compared to the traditional ANFIS model.

\section{Conclusions}

In this study a modified adaptive neurofuzzy inference system with smoothing treatment have been developed for predicting the oilfield-increased production under the well stimulation. Three conclusions can be found. (1) An effective method for prediction of oilfield increased production has been put forward. (2) To a certain extent, the novel method can reduce the influence of maximum or minimum data values on the results of the prediction of oilfield-increased production. (3) The MANFIS model was more accurate in 
predicting the values of increased production under the well stimulation compared to the traditional ANFIS model.

\section{Data Availability}

The data used to support the findings of this study are included within the article.

\section{Conflicts of Interest}

The authors declare that they have no conflicts of interest.

\section{Acknowledgments}

This research was partially supported by the Applied Fundamental Research Projects (Major Frontier Projects) of Sichuan Province 16JC0314, the Sichuan Province International Cooperation Project 2017HH0014, the National Youth Science Foundation Project 41702286, and the International Scientific and Technological Cooperation and Exchange $\mathrm{R}$ and $\mathrm{D}$ Project in Sichuan Province 18GJHZ0206.

\section{References}

[1] M. Höök, R. Hirsch, and K. Aleklett, "Giant oil field decline rates and their influence on world oil production," Energy Policy, vol. 37, no. 6, pp. 2262-2272, 2009.

[2] P. A. Carlos, G. Eduardo, and D. Mario, "Modeling and simulation of an acoustic well stimulation method," Wave Motion, vol. 77, pp. 214-228, 2018.

[3] D. C. Digiulio and R. B. Jackson, "Impact to underground sources of drinking water and domestic wells from production well stimulation and completion practices in the pavillion, Wyoming, field," Environmental Science and Technology, vol. 50, no. 19, pp. 4524-4536, 2016.

[4] Y. S. Hu and E. Mackay, "Modelling of geochemical reactions occurring in the gyda field under cold-seawater injection on the basis of producedw-ater-chemistry data and implications for scale management," SPE Production and Operations, vol. 32, no. 4, pp. 449-468, 2014.

[5] L. Chen, Z. Liu, and N. Ma, "Time-delayed polynomial grey system model with the fractional order accumulation," Mathematical Problems in Engineering, vol. 2018, Article ID 3640625, 7 pages, 2018.

[6] G. Wang, T. Ren, Q. Qi, L. Zhang, and Q. Liu, "Prediction of coalbed methane (CBM) production considering bidisperse diffusion: model development, experimental test, and numerical simulation," Energy \& Fuels, vol. 31, no. 6, pp. 5785-5797, 2017.

[7] L. Chen, Z. Liu, and N. Ma, "Optimize production allocation for the oil-gas field basing on a novel grey model," Journal of Natural Gas Geoscience, vol. 4, no. 2, pp. 121-128, 2019.

[8] J.-S. R. Jang, "ANFIS: adaptive-network-based fuzzy inference system," IEEE Transactions on Systems, Man, and Cybernetics, vol. 23, no. 3, pp. 665-685, 1993.

[9] A. Shabri, "A Hybrid wavelet analysis and adaptive neurofuzzy inference system for drought forecasting," Applied Mathematical Sciences, vol. 8, no. 139, pp. 6909-6918, 2014.

[10] H. M. Azamathulla, A. A. B. Ghani, and S. Y. Fei, "ANFISbased approach for predicting sediment transport in clean sewer," Applied Soft Computing, vol. 12, no. 3, pp. 1227-1230, 2012.
[11] J. P. S. Catalao, H. M. I. Pousinho, and V. M. F. Mendes, "Hybrid wavelet-PSO-ANFIS approach for short-term wind power forecasting in Portugal," IEEE Transactions on Sustainable Energy, vol. 2, no. 1, pp. 50-59, 2010.

[12] R. Singh, A. Kainthola, and T. N. Singh, "Estimation of elastic constant of rocks using an ANFIS approach," Applied Soft Computing, vol. 12, no. 1, pp. 40-45, 2012.

[13] I. Yilmaz and O. Kaynar, "Multiple regression, ANN (RBF, MLP) and ANFIS models for prediction of swell potential of clayey soils," Expert Systems with Applications, vol. 38, no. 5, pp. 5958-5966, 2011.

[14] A. Mosavi, P. Ozturk, and K. W. Chau, "Flood prediction using machine learning models: literature review," Water, vol. 10, no. 11, pp. 1-40, 2018.

[15] A. T. Hammid, M. H. B. Sulaiman, and A. N. Abdalla, "Prediction of small hydropower plant power production in Himreen Lake dam (HLD) using artificial neural network," Alexandria Engineering Journal, vol. 57, no. 1, pp. 211-221, 2018.

[16] M. Dehghani, R. M. Hossein, F. Hooshyaripor et al., "Prediction of hydropower generation using grey wolf optimization adaptive neuro-fuzzy inference system," Energies, vol. 12, no. 2, pp. 1-20, 2019.

[17] M. Mostafaei, H. Javadikia, and L. Naderloo, "Modeling the effects of ultrasound power and reactor dimension on the biodiesel production yield: comparison of prediction abilities between response surface methodology (RSM) and adaptive neuro-fuzzy inference system (ANFIS)," Energy, vol. 115, pp. 626-636, 2016.

[18] M. Mostafaei, "ANFIS models for prediction of biodiesel fuels cetane number using desirability function," Fuel, vol. 216, pp. 665-672, 2018.

[19] M. Aghbashlo, S. Hosseinpour, M. Tabatabaei, and A. Dadak, "Fuzzy modeling and optimization of the synthesis of biodiesel from waste cooking oil (WCO) by a low power, high frequency piezo-ultrasonic reactor," Energy, vol. 132, pp. 65-78, 2017.

[20] D. Janiga, R. Czarnota, J. Stopa, and P. Wojnarowski, "Selfadapt reservoir clusterization method to enhance robustness of well placement optimization," Journal of Petroleum Science and Engineering, vol. 173, pp. 37-52, 2019.

[21] M. Sayyafzadeh, "Reducing the computation time of well placement optimisation problems using self-adaptive metamodelling," Journal of Petroleum Science and Engineering, vol. 151, pp. 143-158, 2017.

[22] M. Vardian, H. R. Nasriani, R. Faghihi, A. Vardian, and S. Jowkar, "Porosity and permeability prediction from well logs using an adaptive neuro-fuzzy inference system in a naturally fractured gas-condensate reservoir," Energy Sources, Part A: Recovery, Utilization, and Environmental Effects, vol. 38, no. 3, pp. 435-441, 2016.

[23] A. H. Haghiabi, A. Parsaie, and S. Ememgholizadeh, "Prediction of discharge coefficient of triangular labyrinth weirs using adaptive neuro fuzzy inference system," Alexandria Engineering Journal, vol. 57, no. 3, pp. 1773-1782, 2018.

[24] D. Janiga, R. Czarnota, J. Stopa, P. Wojnarowski, and P. Kosowski, "Utilization of nature-inspired algorithms for gas condensate reservoir optimization," Soft Computing, vol. 23, no. 14, pp. 5619-5631, 2019.

[25] X. Wang, P. Du, and J. Shen, "Smoothing splines with varying smoothing parameter," Biometrika, vol. 100, no. 4, pp. 955970, 2013. 
[26] M. Karppa, P. Kaski, and J. Kohonen, "A faster subquadratic algorithm for finding outlier correlations," ACM Transactions on Algorithms, vol. 14, no. 3, pp. 1288-1305, 2018.

[27] M. Buragohain and C. Mahanta, "A novel approach for ANFIS modelling based on full factorial design," Applied Soft Computing, vol. 8, no. 1, pp. 609-625, 2008. 


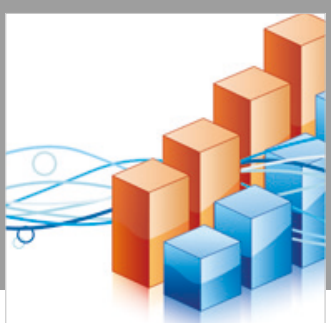

Advances in

Operations Research

\section{-n-m}
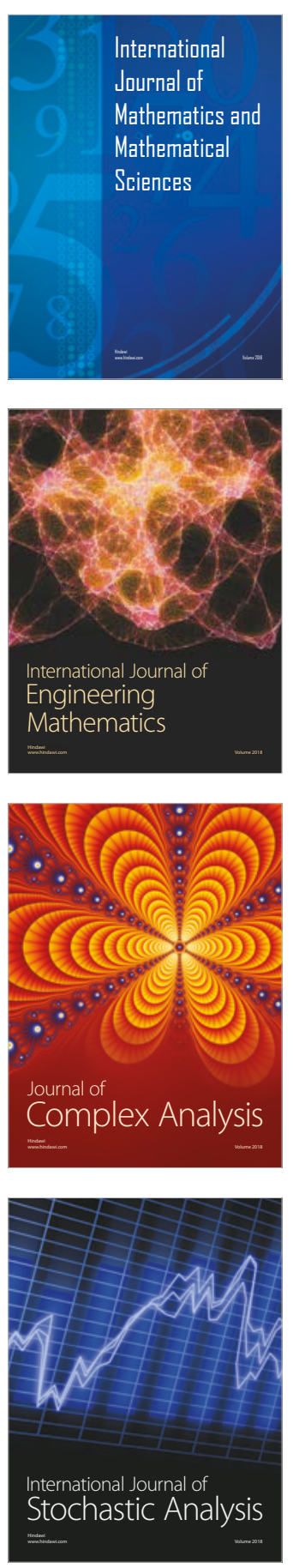
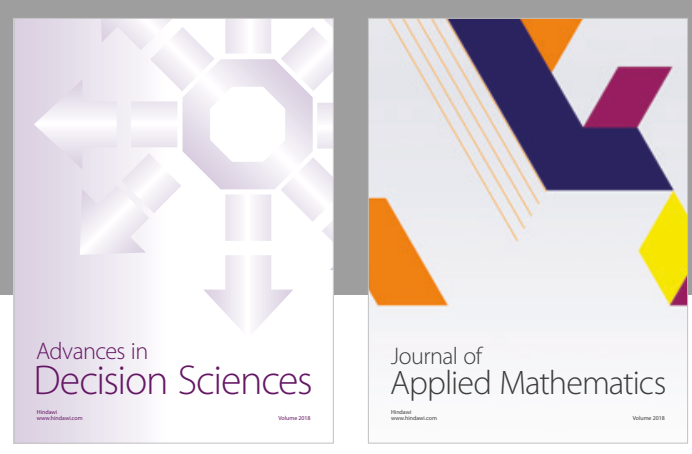

Journal of

Applied Mathematics
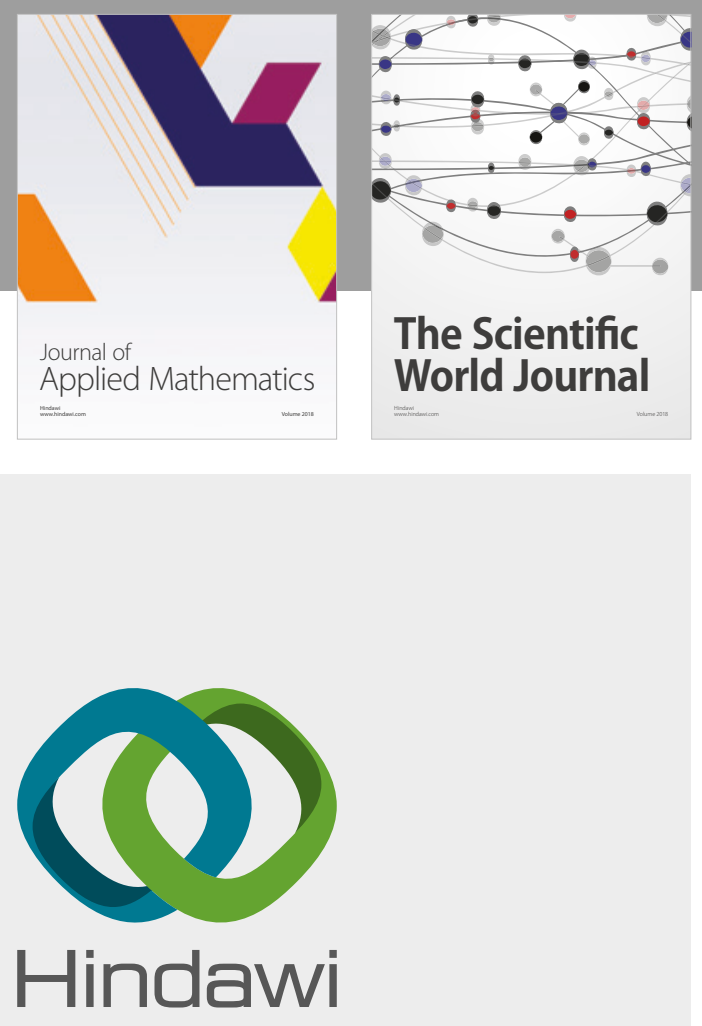

Submit your manuscripts at

www.hindawi.com

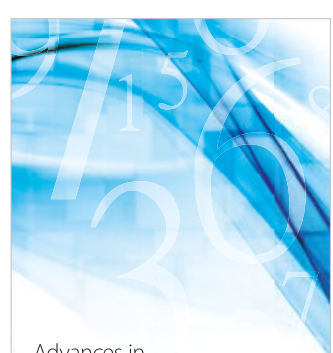

Advances in
Numerical Analysis
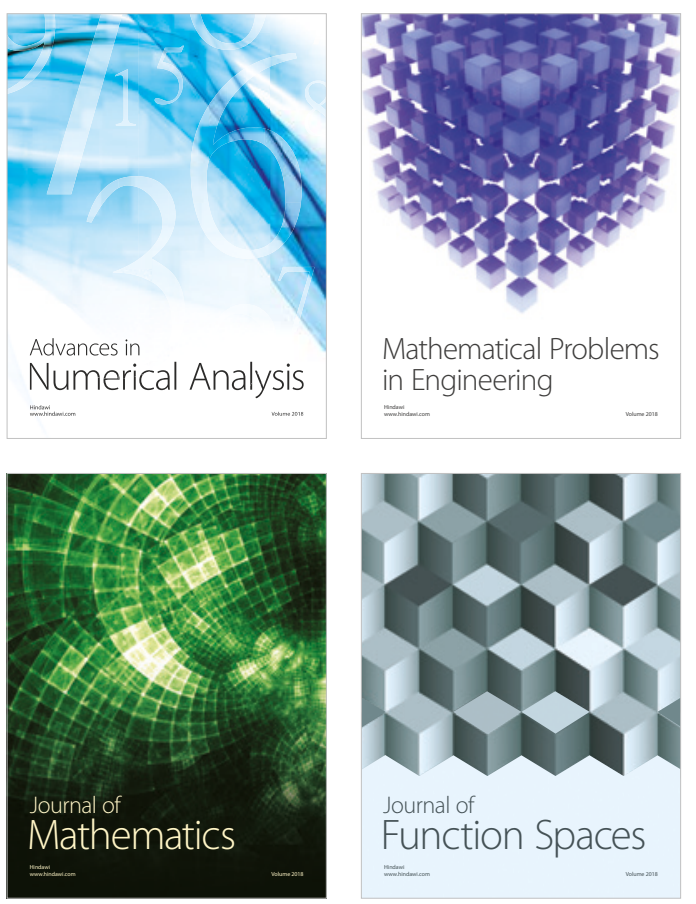

Mathematical Problems in Engineering

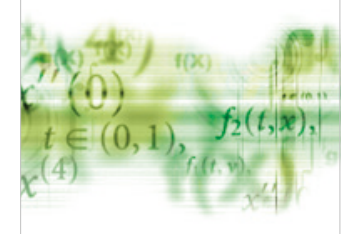

International Journal of

Differential Equations

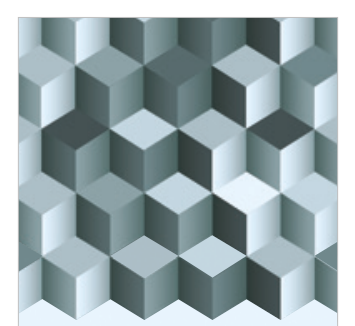

Journal of

Function Spaces

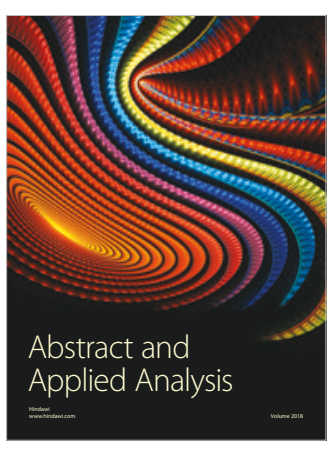

The Scientific

World Journal

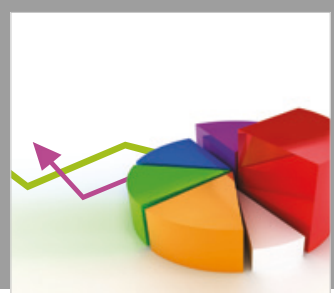

Journal of

Probability and Statistics
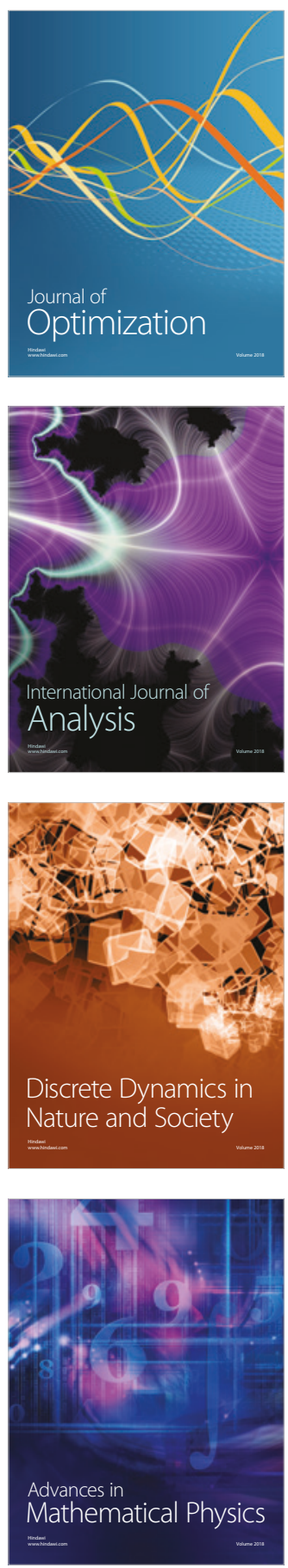